\title{
Radiation and Chemical Reaction Effects on Unsteady Double Diffusive Convective Flow past an Oscillating Surface with Constant Heat Flux
}

\author{
Arpita Jain \\ Department of Mathematics, JECRC UDML College of Engineering, Jaipur 302028, India \\ Correspondence should be addressed to Arpita Jain; arpita_252@rediffmail.com
}

Received 16 June 2013; Accepted 13 July 2013

Academic Editors: J. Ancheyta and M. Kostoglou

Copyright (c) 2013 Arpita Jain. This is an open access article distributed under the Creative Commons Attribution License, which permits unrestricted use, distribution, and reproduction in any medium, provided the original work is properly cited.

This paper presents an analysis of combined heat and mass transfer flow past an oscillating vertical plate under the action of radiation effects and chemical reaction when heat is supplied to the plate at constant rate. The governing equations are solved in closed form by Laplace-transform technique. The results are obtained for temperature, concentration, velocity, skin friction, Nusselt number, and Sherwood number. The effects of various parameters on flow variables are illustrated graphically, and the physical aspects of the problem are discussed.

\section{Introduction}

Free convection arises in the fluid when temperature changes cause density variation leading to buoyancy forces acting on the fluid elements. The most common example of free convection is the atmospheric flow which is driven by temperature differences. Natural convection has been analyzed extensively by many investigators. Some of them are Revankar [1] Li et al. [2].

Sometimes along with the free convection currents caused by difference in temperature the flow is also affected by the differences in concentration or material constitution. There are many situations where convection heat transfer phenomena are accompanied by mass transfer also. When mass transfer takes place in a fluid at rest, the mass is transferred purely by molecular diffusion resulting from concentration gradients. For low concentration of the mass in the fluid and low mass transfer rates, the convective heat and mass transfer processes are similar in nature. A number of investigations have already been carried out with combined heat and mass transfer under the assumption of different physical situations. The illustrative examples of mass transfer can be found in the book of Cussler [3]. Combined heat and mass transfer flow past a surface are analyzed by Chaudhary and Arpita. [4], Muthucumaraswamy et al. [5, 6] and Rajput and Kumar [7] with different physical conditions. Juncu [8] pioneered unsteady heat and mass transfer flow past a surface by numerical method.

Combined heat and mass transfer problems with chemical reaction are of importance in many processes and have, therefore, received a considerable amount of attention in recent years. Chemical reaction can be codified as either homogeneous or heterogeneous processes. A homogeneous reaction is one that occurs uniformly through a given phase. In contrast, a heterogeneous reaction takes place in a restricted region or within the boundary of a phase. A reaction is said to be first order if the rate of reaction is directly proportional to the concentration itself which has many applications in different chemical engineering processes and other industrial applications such as polymer production, manufacturing of ceramics or glassware, and food processing. Das et al. [9] considered the effects of first order chemical reaction on the flow past an impulsively started infinite vertical plate with constant heat flux and mass transfer. Muthucumaraswamy and Meenakshisundaram [10] studied chemical reaction effects on vertical oscillating plate with variable temperature.

In the above mentioned studies, the effect of radiation on flow has not been considered. Actually, many processes in new engineering areas occur at high temperature, 
and knowledge of radiation heat transfer becomes imperative for the design of the pertinent equipment. Nuclear power plants, gas turbines, and the various propulsion devices for aircraft, missiles, satellites, and space vehicles are examples of such engineering areas. Unsteady free convection flow past a vertical plate with chemical reaction under different temperature condition on the plate is elucidated by Neog and Das Rudra [11], and Rajesh et al. [12]. Thermal radiation effect on flow past a vertical plate with mass transfer is examined by Muralidharan and Muthucumaraswamy [13] and Rajput and Kumar [14]. Natural convective flow past an oscillating plate with constant mass flux in the presence of radiation is studied by Chaudhary and Jain [15].

The effects of radiation on free convection on the accelerated flow of a viscous incompressible fluid past an infinite vertical plate have many important technological applications in the astrophysical, geophysical, and engineering problem.

However, it seems less attention was paid on hydromagnetic free convection flows near a vertical plate subjected to a constant heat flux boundary condition even though this situation is involved in many engineering applications. Ogulu and Makinde [16] and Narahari and Debnath [17] examined the flow past a surface with constant heat flux. Free convection effects on flow past an infinite vertical accelerated with constant heat flux are pioneered by Chaudhary and Arpita [18].

Hence, the objective of this paper is to study radiation and chemical reaction effects on unsteady double diffusive convective flow past an oscillating vertical plate when heat is supplied to it at constant rate.

\section{Mathematical Analysis}

We consider a two-dimensional flow of an incompressible and electrically conducting viscous fluid along an infinite vertical plate. The $x^{\prime}$-axis is taken on the infinite plate and parallel to the free stream velocity and $y^{\prime}$-axis normal to it. Initially, the plate and the fluid are at same temperature $T_{\infty}^{\prime}$ with concentration level $C_{\infty}^{\prime}$ at all points. At time $t^{\prime}>0$, the plate concentration is changed to $C_{w}^{\prime}$ with heat supplied at a Constant rate to the plate and it starts oscillating with a velocity $U_{R} \cos \omega^{\prime} t^{\prime}$ in its own plane. It is assumed that there exists a homogeneous chemical reaction of first order with constant rate $K_{l}$ between the diffusing species and the fluid. Since the plate is infinite in extent therefore the flow variables are the functions of $y^{\prime}$ and $t^{\prime}$ only. The fluid is considered to be gray absorbing-emitting radiation but non scattering medium. The radiative heat flux in the $x^{\prime}$ direction is considered negligible in comparison with of $y^{\prime}$ direction. Then neglecting viscous dissipation, heat produced by chemical reaction, and assuming variation of density in the body force term (Boussinesq's approximation), the problem can be governed by the following set of equations:

$$
\frac{\partial T^{\prime}}{\partial t^{\prime}}=\frac{\kappa}{\rho C_{p}} \frac{\partial^{2} T^{\prime}}{\partial y^{\prime 2}}-\frac{1}{\rho C_{p}} \frac{\partial q_{r}}{\partial y^{\prime}},
$$

$$
\begin{gathered}
\frac{\partial C^{\prime}}{\partial t^{\prime}}=D \frac{\partial^{2} C^{\prime}}{\partial y^{\prime 2}}-k_{l} C^{\prime}, \\
\frac{\partial u^{\prime}}{\partial t^{\prime}}=\nu \frac{\partial^{2} u^{\prime}}{\partial y^{\prime 2}}+g \beta\left(T^{\prime}-T_{\infty}^{\prime}\right)+g \beta_{c}\left(C^{\prime}-C_{\infty}^{\prime}\right),
\end{gathered}
$$

with following initial and boundary conditions:

$$
\begin{gathered}
u^{\prime}=0, \quad T^{\prime}=T_{\infty}^{\prime}, \quad C^{\prime}=C_{\infty}^{\prime} \quad \forall y^{\prime}, t^{\prime} \leq 0, \\
u^{\prime}=U_{R} \cos \omega^{\prime} t^{\prime}, \quad \frac{\partial T^{\prime}}{\partial y^{\prime}}=-\frac{q}{\kappa}, \\
C^{\prime}=C_{w}^{\prime} \quad \text { at } y^{\prime}=0, t^{\prime}>0, \\
u^{\prime} \longrightarrow 0, \quad T^{\prime} \longrightarrow T_{\infty}^{\prime}, \quad C^{\prime} \longrightarrow C_{\infty}^{\prime} \\
\text { as } y^{\prime} \longrightarrow \infty, t^{\prime}>0 .
\end{gathered}
$$

The radiative heat flux term, by using Rosseland's approximation, is given by

$$
q_{r}=-\frac{4 \sigma^{\prime}}{3 \kappa^{*}} \frac{\partial T^{\prime 4}}{\partial y^{\prime}} .
$$

We assume that the temperature differences within the flow are such that $T^{\prime 4}$ may be expressed as a linear function of the temperature $T^{\prime}$. This is accomplished by expanding $T^{\prime 4}$ in a Taylor series about $T_{\infty}^{\prime}$ and neglecting higher-order terms.

One has

$$
T^{\prime 4} \simeq 4 T_{\infty}^{\prime 3} T^{\prime}-3 T_{\infty}^{\prime 4} .
$$

By using (5) and (6), (1) gives

$$
\rho C_{p} \frac{\partial T^{\prime}}{\partial t^{\prime}}=\kappa \frac{\partial^{2} T^{\prime}}{\partial y^{\prime 2}}+\frac{16 \sigma^{\prime} T_{\infty}^{\prime 3}}{3 \kappa^{*}} \frac{\partial^{2} T^{\prime}}{\partial y^{\prime 2}} .
$$

Introducing the following dimensionless quantities:

$$
\begin{aligned}
& t=\frac{t^{\prime}}{t_{R}}, \quad y=\frac{y^{\prime}}{L_{R}}, \quad u=\frac{u^{\prime}}{U_{R}}, \\
& \omega=\omega^{\prime} t_{R}, \quad k=\frac{U_{R}^{2} k_{l}}{v^{2}}, \\
& \operatorname{Pr}=\frac{\mu \mathrm{C}_{p}}{\kappa}, \quad \mathrm{Sc}=\frac{\nu}{D}, \\
& \theta=\frac{T^{\prime}-T_{\infty}^{\prime}}{q \nu / \kappa U_{R}}, \quad G=\frac{g \beta q \nu^{2}}{\kappa U_{R}^{4}}, \\
& C=\frac{C^{\prime}-C_{\infty}^{\prime}}{C_{w}^{\prime}-C_{\infty}^{\prime}}, \quad \mathrm{Gm}=\frac{v g \beta_{C}\left(C_{w}^{\prime}-C_{\infty}^{\prime}\right)}{U_{R}^{3}}, \\
& k=\frac{v k_{l}}{U_{R}^{2}}, \quad R=\frac{\kappa^{*} \kappa}{4 \sigma^{\prime} T_{\infty}^{\prime 3}}, \\
& \Delta T=T_{w}^{\prime}-T_{\infty}^{\prime}, \quad U_{R}=(\nu g \beta \Delta t)^{1 / 3}, \\
& L_{R}=\left(\frac{g \beta \Delta T}{v^{2}}\right)^{-1 / 3}, \quad t_{R}=(g \beta \Delta T)^{-2 / 3} v^{1 / 3} \text {, }
\end{aligned}
$$


the governing equations (1) to (3) reduce to the following nondimensional form:

$$
\begin{gathered}
\operatorname{Pr} \frac{\partial \theta}{\partial t}=\left(1+\frac{4}{3 R}\right) \frac{\partial^{2} \theta}{\partial y^{2}} \\
\frac{\partial C}{\partial t}=\frac{1}{S c} \frac{\partial^{2} C}{\partial y^{2}}-k C, \\
\frac{\partial u}{\partial t}=\frac{\partial^{2} u}{\partial y^{2}}+G \theta+G m C
\end{gathered}
$$

with the following initial and boundary conditions:

$$
\begin{gathered}
u=0, \quad \theta=0, \quad C=0 \quad \forall y, t \leq 0, \\
u=\cos \omega \mathrm{t}, \quad \frac{\partial \theta}{\partial y}=-1, \quad C=1 \quad \text { at } y=0, t>0, \\
u \longrightarrow 0, \quad \theta \longrightarrow 0, \quad C \longrightarrow 0 \quad \text { as } y \longrightarrow \infty, t>0 .
\end{gathered}
$$

On taking Laplace-transform of (9) and boundary conditions (10), we get

$$
\begin{aligned}
& \left(1+\frac{4}{3 R}\right) \frac{d^{2} \bar{\theta}}{d y^{2}}-p \operatorname{Pr} \bar{\theta}=0 \\
& \frac{d^{2} \bar{\phi}}{d y^{2}}(k+p \mathrm{Sc}) \vec{C}=0 \\
& \frac{d^{2} \bar{u}}{d y^{2}}-p \bar{u}=-G \bar{\theta}(y, p)-G m \vec{C}, \\
& \bar{u}=\frac{p}{p^{2}+\omega^{2}}, \quad \frac{d \bar{\theta}}{d y}=-\frac{1}{p}, \quad \bar{C}=\frac{1}{p}, \\
& \text { at } y=0, t>0 \text {, } \\
& \bar{u} \longrightarrow 0, \quad \bar{\theta} \longrightarrow 0, \quad \bar{C} \longrightarrow 0 \quad \text { as } y \longrightarrow \infty, t>0, \\
& \bar{\theta}(y, p)=\sqrt{\frac{H}{\operatorname{Pr}}} \frac{\exp (-y \sqrt{p \operatorname{Pr} / H})}{p^{3 / 2}}, \\
& \bar{C}(y, p)=\frac{\exp (-y \sqrt{(k \mathrm{Sc}+p \mathrm{Sc})})}{p},
\end{aligned}
$$
get

$$
\begin{aligned}
\bar{u}(y, p)= & \frac{p \exp (-y \sqrt{p})}{p^{2}+\omega^{2}}+\sqrt{\frac{H}{\operatorname{Pr}}} \frac{G \exp (-y \sqrt{p})}{p^{5 / 2}((\operatorname{Pr} / H)-1)} \\
& +\frac{\mathrm{Gm} \exp (-y \sqrt{p})}{p(\mathrm{Sc}-1)(p+(k \mathrm{Sc} /(\mathrm{Sc}-1)))} \\
& -\frac{\mathrm{Gm}}{p(\mathrm{Sc}-1)(p+(k \mathrm{Sc} /(\mathrm{Sc}-1)))} \\
& \times\{\exp (-y \sqrt{p \mathrm{Sc}+k \mathrm{Sc}})\} \\
& -\sqrt{\frac{H}{\operatorname{Pr}}} \frac{G \exp (-y \sqrt{p \operatorname{Pr} / H})}{p^{5 / 2}\left(\frac{\operatorname{Pr}}{H}-1\right)} .
\end{aligned}
$$

On taking inverse Laplace-transform of (13), we get

$$
\begin{array}{r}
\theta=\sqrt{\frac{t H}{\pi \operatorname{Pr}}} \operatorname{erfc}\left(\frac{-\eta^{2} \operatorname{Pr}}{H}\right)-\eta \sqrt{t} \operatorname{erfc}\left(\eta \sqrt{\frac{\operatorname{Pr}}{H}}\right), \\
C=\frac{1}{2}\{\exp (2 \eta \sqrt{k \operatorname{Sc} t}) \operatorname{erfc}(\eta \sqrt{\mathrm{Sc}}+\sqrt{k t}) \\
+\exp (-2 \eta \sqrt{k S c t}) \operatorname{erfc}(\eta \sqrt{S c}-\sqrt{k t})\} .
\end{array}
$$

For $\operatorname{Pr}=S c \neq 1$, one has

$$
\begin{aligned}
u= & \frac{\exp (i \omega t)}{4} \\
\times & \{\exp (2 \eta \sqrt{i \omega t}) \operatorname{erfc}(\eta+\sqrt{i \omega t}) \\
& +\exp (-2 \eta \sqrt{i \omega t}) \operatorname{erfc}(\eta-\sqrt{i \omega t})\}+\frac{\exp (-i \omega t)}{4} \\
\times & \{\exp (2 \eta \sqrt{-i \omega t}) \operatorname{erfc}(\eta+\sqrt{-i \omega t}) \\
& +\exp (-2 \eta \sqrt{-i \omega t}) \operatorname{erfc}(\eta-\sqrt{-i \omega t})\} \\
+ & \sqrt{\frac{H}{\operatorname{Pr}}} \frac{G t^{3 / 2}}{3((\operatorname{Pr} / H)-1)}\left\{\frac{4}{\sqrt{\pi}}\left(1+\eta^{2}\right) \exp \left(-\eta^{2}\right)\right. \\
+ & \sqrt{\frac{H}{\operatorname{Pr}}} \frac{G t^{3 / 2}}{3(1-(\operatorname{Pr} / H))} \\
\times & \left\{\frac{4}{\sqrt{\pi}}\left(1+\eta^{2} \frac{\operatorname{Pr}}{H}\right) \exp \left(-\eta^{2} \frac{\operatorname{Pr}}{H}\right)\right. \\
& \left.-\eta \sqrt{\frac{\operatorname{Pr}}{H}}\left(6+4 \eta^{2} \frac{\operatorname{Pr}}{H}\right) \operatorname{erfc}\left(\eta \sqrt{\frac{\operatorname{Pr}}{H}}\right)\right\}
\end{aligned}
$$




$$
\begin{aligned}
& +\frac{\mathrm{Gm}}{k \mathrm{Sc}} \operatorname{erfc}(\eta)-\frac{\mathrm{Gm}}{2 k \mathrm{Sc}} \exp \left(\frac{k \mathrm{Sc} t}{1-\mathrm{Sc}}\right) \\
& \times\left\{\left(\exp \left(2 \eta \sqrt{\frac{k \mathrm{Sc} t}{1-\mathrm{Sc}}}\right) \operatorname{erfc}\left(\eta+\sqrt{\frac{k \mathrm{Sc} t}{1-\mathrm{Sc}}}\right)\right.\right. \\
& +\exp \left(-2 \eta \sqrt{\frac{k \mathrm{Sc} t}{1-\mathrm{Sc}}}\right) \operatorname{erfc}\left(\eta-\sqrt{\left.\left.\frac{k \mathrm{Sc} t}{1-\mathrm{Sc}}\right)\right\}}\right. \\
& \left.-\frac{\mathrm{Gm}}{2 k \mathrm{Sc}} \exp \left(\frac{k \mathrm{Sc} t}{1-\mathrm{Sc}}\right)\right\} \\
& \times\left\{\left(\exp \left(2 \eta \sqrt{\frac{k \mathrm{Sc} t}{1-\mathrm{Sc}}}\right) \operatorname{erfc}\left(\eta \sqrt{\mathrm{Sc}}+\sqrt{\frac{k t}{1-\mathrm{Sc}}}\right)\right.\right. \\
& \left.+\exp \left(-2 \eta \sqrt{\frac{k \mathrm{Sc} t}{1-\mathrm{Sc}}}\right) \operatorname{erfc}\left(\eta \sqrt{\mathrm{Sc}}-\sqrt{\frac{k t}{1-\mathrm{Sc}}}\right)\right\} \\
& +\frac{\mathrm{Gm}}{2 k \mathrm{Sc}}\{(\exp (2 \eta \sqrt{k \mathrm{Sc} t}) \operatorname{erfc}(\eta \sqrt{\mathrm{Sc}}+\sqrt{k t}) \\
& +(\exp (-2 \eta \sqrt{k \mathrm{Sc} t}) \operatorname{erfc}(\eta \sqrt{\mathrm{Sc}}-\sqrt{k t})\}
\end{aligned}
$$

where $H=1+(4 / 3 R)$ and for $\operatorname{Pr}=\mathrm{Sc}=1$ when $R \rightarrow \infty$,

$$
\begin{aligned}
u=\frac{\exp (i \omega t)}{4}\{\exp (2 \eta \sqrt{i \omega t}) \operatorname{erfc}(\eta+\sqrt{i \omega t}) \\
+\exp (-2 \eta \sqrt{i \omega t}) \operatorname{erfc}(\eta-\sqrt{i \omega t})\} \\
+\frac{\exp (-i \omega t)}{4} \\
\times\{\exp (2 \eta \sqrt{-i \omega t}) \operatorname{erfc}(\eta+\sqrt{-i \omega t}) \\
\quad+\exp (-2 \eta \sqrt{-i \omega t}) \operatorname{erfc}(\eta-\sqrt{-i \omega t})\}
\end{aligned}
$$

In expressions, erfc $\left(x_{1}+i y_{1}\right)$ is complementary error function of complex argument which can be calculated in terms of tabulated functions in Abramowitz and Stegun [19]. The tables given in Abramowitz and Stegun [19] do not give $\operatorname{erfc}\left(x_{1}+i y_{1}\right)$ directly but an auxiliary function $W_{1}\left(x_{1}+i y_{1}\right)$ which is defined as

$$
\operatorname{erfc}\left(x_{1}+i y_{1}\right)=W_{1}\left(-y_{1}+i x_{1}\right) \exp \left\{-\left(x_{1}+i y_{1}\right)^{2}\right\}
$$

Some properties of $W_{1}\left(x_{1}+i y_{1}\right)$ are

$$
\begin{gathered}
W_{1}\left(-x_{1}+i y_{1}\right)=W_{2}\left(x_{1}+i y_{1}\right) \\
W_{1}\left(x_{1}-i y_{1}\right)=2 \exp \left\{-\left(x_{1}-i y_{1}\right)^{2}\right\}-W_{2}\left(x_{1}+i y_{1}\right)
\end{gathered}
$$

where $W_{2}\left(x_{1}+i y_{1}\right)$ is complex conjugate of $W_{1}\left(x_{1}+i y_{1}\right)$.

\section{Skin Friction}

From velocity field, skin friction at the plate in nondimensional form is expressed as

$$
\begin{aligned}
\tau=-\left(\frac{\partial u}{\partial y}\right)_{y=0}, \\
+\frac{\exp (i \omega t)}{2 \sqrt{t}}\{\sqrt{i \omega t} \operatorname{erf}(\sqrt{i \omega t})\}+\frac{\exp (-i \omega t)}{2 \sqrt{t}} \\
\times\{\sqrt{-i \omega t} \operatorname{erf}(\sqrt{-i \omega t})\}+\frac{G t H}{(\operatorname{Pr}-H)} \sqrt{\frac{H}{\operatorname{Pr}}}\left(1-\sqrt{\frac{\operatorname{Pr}}{H}}\right) \\
+\frac{1}{\sqrt{\pi t}}-\frac{\mathrm{Gm}}{k \mathrm{Sc}} \exp \left(\frac{k \mathrm{Sct}}{1-\mathrm{Sc}}\right) \operatorname{erf}\left(\sqrt{\frac{k \mathrm{Sct}}{1-\mathrm{Sc}}}\right) \sqrt{\frac{k \mathrm{Sc}}{1-\mathrm{Sc}}} \\
+\frac{\mathrm{Gm}}{k \mathrm{Sc}} \exp \left(\frac{k \mathrm{Sct}}{1-\mathrm{Sc}}\right) \operatorname{erf}\left(\sqrt{\frac{k t}{1-\mathrm{Sc}}}\right) \\
\quad \times \sqrt{\frac{k \mathrm{Sc}}{1-\mathrm{Sc}}-\frac{\mathrm{Gm}}{k \mathrm{Sc}} \sqrt{k \mathrm{Sc}} \operatorname{erf}(\sqrt{k t}) .}
\end{aligned}
$$

\section{Nusselt Number}

From temperature field, the rate of heat transfer in nondimensional form is expressed as

$$
\mathrm{Nu}=-\left.\frac{1}{\theta(0)} \frac{\partial \theta}{\partial y}\right|_{y=0}=+\frac{1}{\theta(0)}=\sqrt{\frac{\pi \mathrm{Pr}}{t H}} .
$$

\section{Sherwood Number}

From the concentration field, the rate of concentration transfer, expressed in nondimensional form, is given by

$$
\mathrm{Sh}=-\left.\frac{\partial \varphi}{\partial y}\right|_{y=0}=\sqrt{\frac{k \mathrm{Sc}}{2}}\left(2+\frac{1}{2} \sqrt{\frac{\mathrm{Sc}}{t}} \exp (-k t)\right) .
$$

\section{Discussion}

In order to get physical insight into the problem, the values of Schmidt number are chosen to represent the presence of species by hydrogen $(0.22)$, water vapour $(0.60)$, ammonia (0.78) and Carbon dioxide $(0.96)$ at $25^{\circ} \mathrm{C}$ temperature and 1 atmospheric pressure. The values of $\operatorname{Pr}$ are chosen 0.71 , 7 which represent air and water, respectively, at $20^{\circ} \mathrm{C}$ temperature and 1 atmospheric pressure. The values of radiation parameter and chemical reaction parameter are chosen arbitrarily. Only real values of solutions are considered for plotting graphs.

Figure 1 reveals temperature profiles against $\eta$ (distance from the plate). It is obvious from the figure that the magnitude of temperature is maximum at the plate and then decays to zero asymptotically. Further, the magnitude of the temperature for air is greater than that of water. 


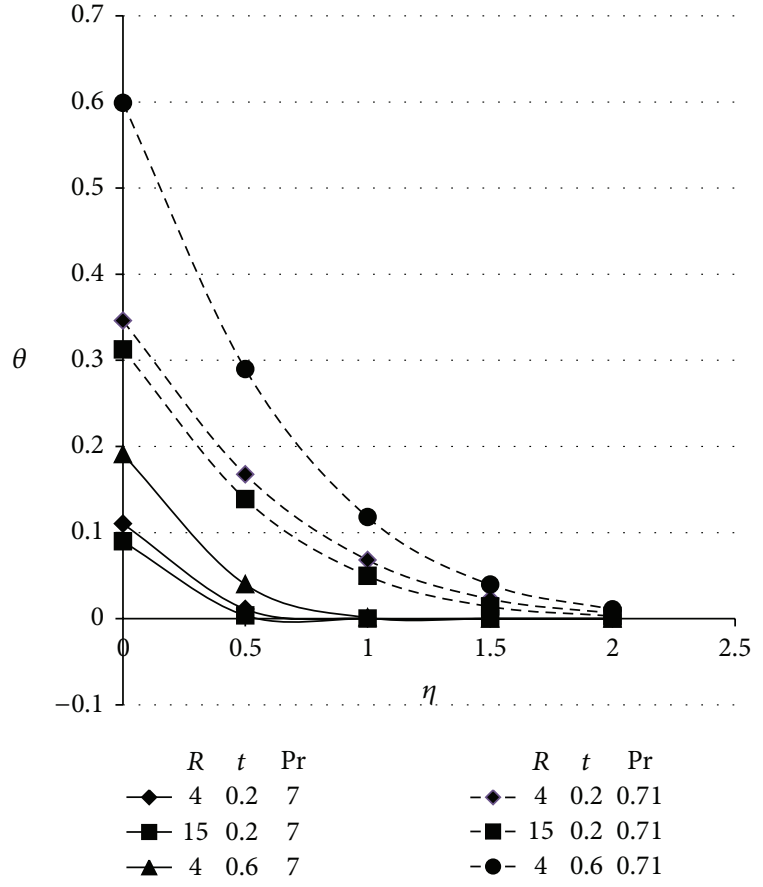

Figure 1: Temperature profile.

This is due to the fact that thermal conductivity of fluid decreases with increasing Pr, resulting in a decrease in thermal boundary layer thickness. It is also seen that it decreases steeply for $\operatorname{Pr}=7$ than that of $\operatorname{Pr}=0.71$. Furthermore, it is noticed that an increase in radiation parameter from 4 to 15 the temperature marginally decreases. It is obvious since the radiation parameter defines the relative contribution of conduction heat transfer to the thermal radiation transfer. Further, it increases with an increase in time.

The species concentration profile against $\eta$ is plotted in Figure 2. It is observed that the concentration at all points in the flow field decreases with $\eta$ and tends to zero as $\eta \rightarrow \infty$. Furthermore, an increase in the value of Scleads to a fall in the concentration. Physically, it is true since increase of Sc means decrease of molecular diffusivity which results in decrease of concentration boundary layer. Hence, the concentration of species is higher for small values of Sc. It is also observed that concentration decreases with an increase in time.

Figure 3 elucidates the effect of $\omega t$ and Pr on the velocity. It is evident from Figure 3 that the velocity increases and attains its maximum value in the vicinity of the plate $(\eta \leq 0.5)$ and then tends to zero asymptotically. It is also noted that both the velocity and the penetration for $\operatorname{Pr}=0.71$ is higher than those of $\operatorname{Pr}=7$. Physically, it is possible because fluids with high Prandtl number have high viscosity and hence move slowly. It is also seen that the velocity decreases with an increase in $\omega t$. Figure 4 illustrates the influences of Sc, $t$, and $\operatorname{Pr}$ on the velocity. It is noticed that the maximum velocity attains near the plate then decreases and vanishes far away from the plate. When $\operatorname{Pr}=7$ and 0.71 it decreases continuously to asymptotic value. Further, they also increases with an increase in time at each point in the flow field for hydrogen gas. Moreover, the effect of time on the velocity is

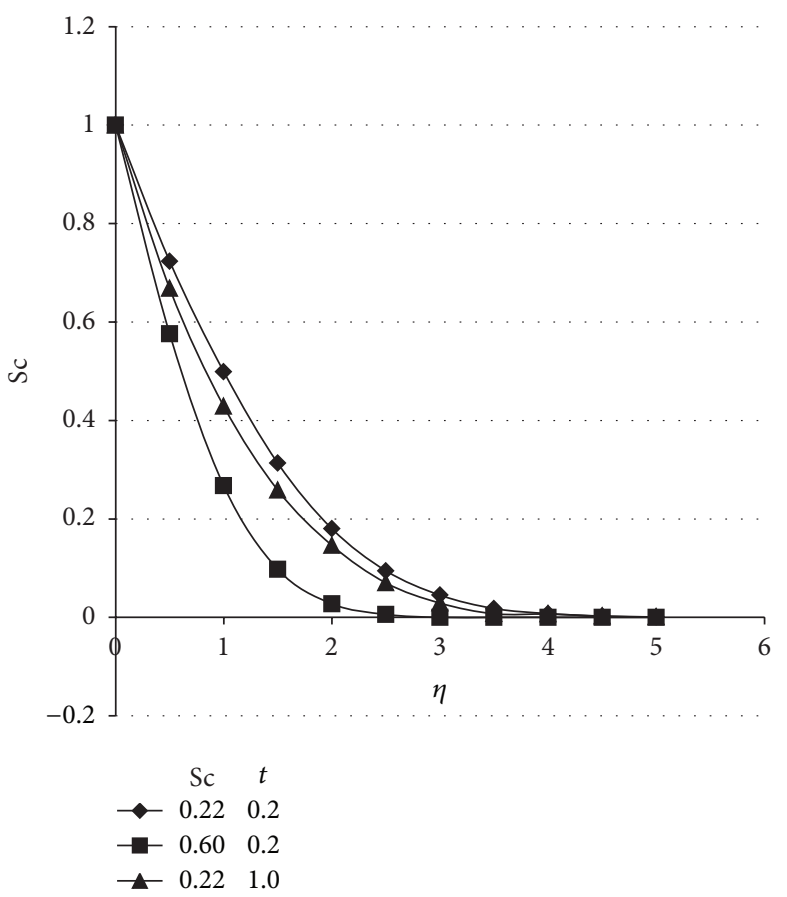

Figure 2: Concentration profile for $k=0.2$.

more dominant than other parameters. Finally, It is observed that the velocity for hydrogen $(\mathrm{Sc}=0.22)$ is higher than that of water vapour $(\mathrm{Sc}=0.60)$ and carbon dioxide $(\mathrm{Sc}=$ 0.96 ) for both air and water. Physically, it is possible since an increase in Sc means increase in kinematic viscosity or viscosity of fluid due to which the velocity of fluid decreases. Figure 5 illustrates the influences of $\mathrm{Gm}, G$ and $\operatorname{Pr}$ on the velocity. The figure reveals that the maximum velocity attains near the plate then decreases and vanish far away from the plate. Moreover, It is observed that an increase in $G, \mathrm{Gm}$ leads to an increase in velocity for both $\mathrm{Pr}=7$ and $\mathrm{Pr}=0.71$ when Hydrogen gas is present in the flow. The reason is that the values of Grashof number and modified Grashof number have the tendency to increase the mass buoyancy effect. The increase in velocity due to increase in $G$ and $\mathrm{Gm}$ is nearer the plate than away from the plate. Figure 6 elucidates the effect of $k$, Pr on velocity profile. It is found that the velocity decreases with an increase in chemical reaction parameter $k$ for both $\operatorname{Pr}=7$ and 0.71 . It is due to the fact that increase in chemical reaction parameter $k$ gives rise to an increase in viscosity of fluid which means velocity boundary layer thickness decreases.

Figure 7 elucidates the effects of parameters Sc, $k, G$, and $\omega t$ on skin friction at the plate at different values of $t$. It is noticed that skin friction decreases sharply with an increase in time and for $\omega t=0$ it becomes negative which means separation of boundary later occurs which is for higher values of $t(t>0.3)$. The figure depicts that skin friction is higher for $\mathrm{Sc}=0.96$ in comparison to $\mathrm{Sc}=0.22$. Physically, it is correct since an increase in Sc serves to increase momentum boundary layer thickness. Further, it decreases with an increase in value of $\mathrm{Gm}$ and marginally increases with an increase in $k$. The increase of $\omega t$ gives rise to an increase in the value of skin friction. 


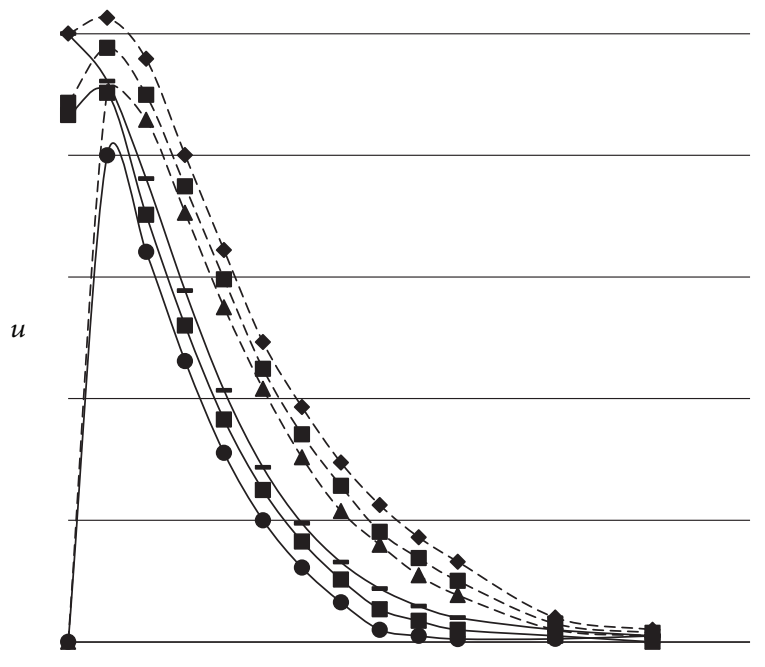

$$
\begin{array}{lc}
\omega t & \operatorname{Pr} \\
--0 & 0.71 \\
-\square \mathrm{pi} / 6 & 0.71 \\
-\mathrm{pi} / 2 & 0.71 \\
-0 & 7 \\
-\mathrm{pi} / 6 & 7 \\
-\mathrm{pi} / 2 & 7
\end{array}
$$

FIgURE 3: Velocity profile for $\mathrm{Sc}=0.22, t=0.2, R=4, k=0.2$, $G=5$, and $\mathrm{Gm}=2$.

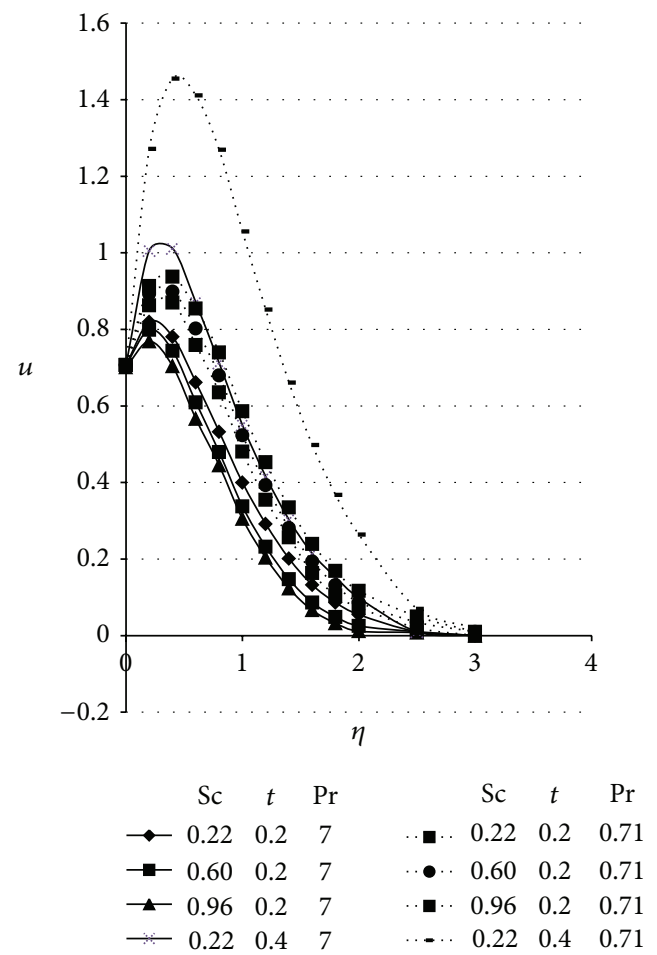

FIGURE 4: Velocity profile $\omega t=\pi / 4, R=4, k=0.2, G=5$, and $\mathrm{Gm}=2$.

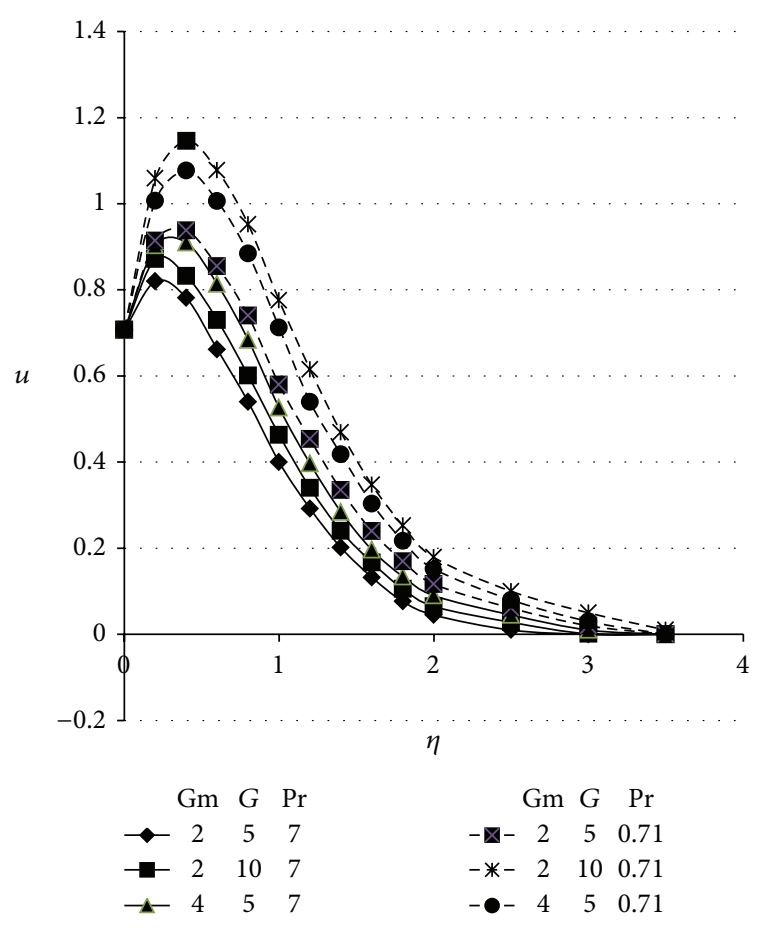

FIgURE 5: Velocity profile for $\omega t=\pi / 4, \mathrm{Sc}=0.22, t=0.2, R=4$, and $k=0.2$.

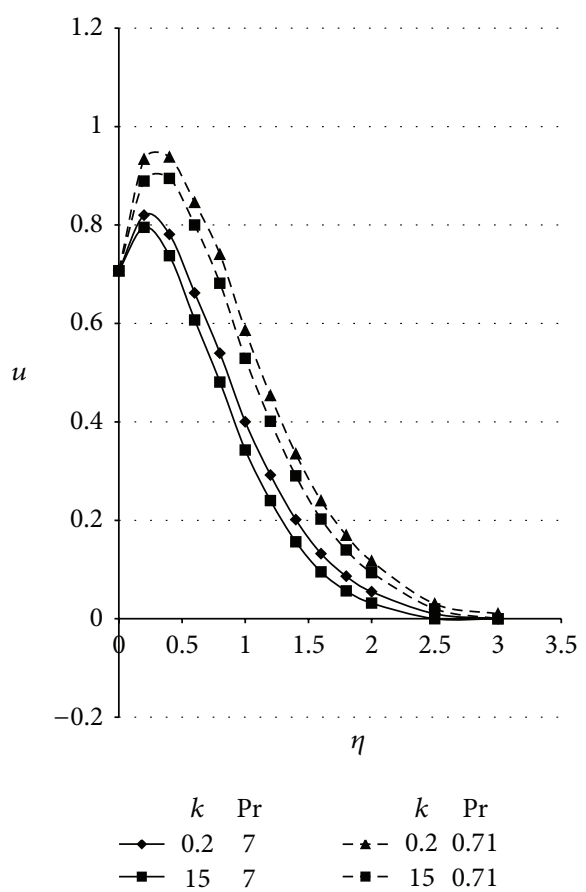

Figure 6: Velocity profile for $\omega t=\pi / 4, \mathrm{Sc}=0.22, t=0.2, f=4$, $G=5$, and $\mathrm{Gm}=2$.

Figure 8 exhibits the Nusselt number against time. It is concluded from the figure that there is an increase in it with an increase in the value of radiation parameter. Furthermore, the value of Nusselt number for water is greater than air. It is consistent with the fact that smaller values of Pr are equivalent to increasing thermal conductivities, and therefore 


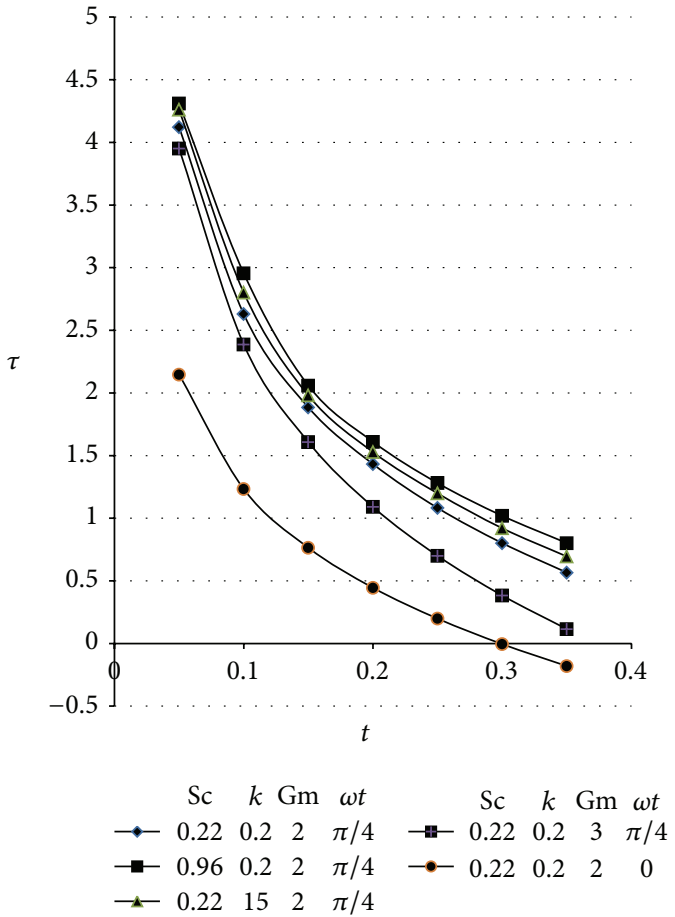

Figure 7: Skin friction for $R=4, G=5, \operatorname{Pr}=7$.

heat is able to diffuse away from the plate more rapidly than higher values of Pr; hence the rate of heat transfer is reduced.

Figure 9 depicts the effect of chemical reaction parameter $k$ and Schmidt number Sc on Sherwood number. It is observed that Sherwood number increases with an increase in $k$ and Sc. Since increase in Sc means decrease in molecular diffusivity this in turn gives rise to increase in Sherwood number as Sherwood number is the ratio of convective and diffusive mass transfer coefficient. Chemical reaction parameter increases the interfacial mass transfer, so Sherwood number increases with an increase in $k$.

\section{Conclusion}

A semi-analytical study has been carried out for flow past a vertical surface in the presence of radiation and chemical reaction when heat is supplied to the plate at constant rate. The dimensionless governing equations are solved by using Laplace transform technique. Numerical evaluations of closed form solutions were performed, and some graphical results were obtained to illustrate the details of flow, heat and mass transfer characteristics, and their dependence on some physical parameters. The physical aspects of the problem are also discussed. The results of the flow problem indicates the following.

(1) Increasing radiation parameter and Prandtl Number, the temperature decreases whereas it increases with increasing time.

(2) Concentration profile decreases with an increase in time and Schmidt number.

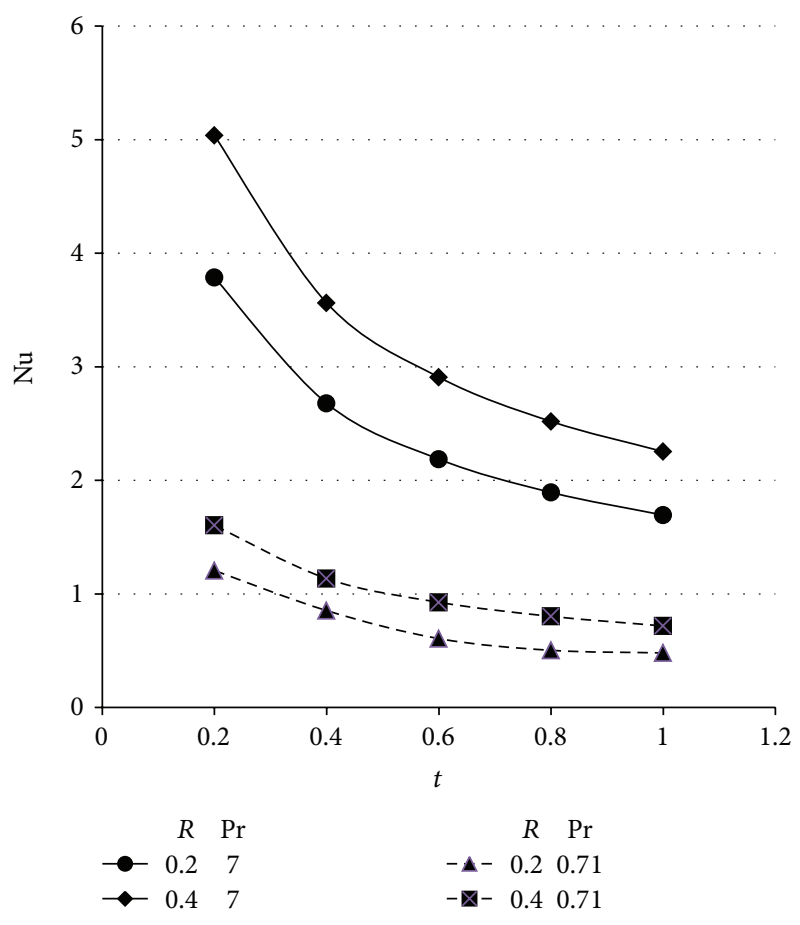

FIGURE 8: Nusselt number.

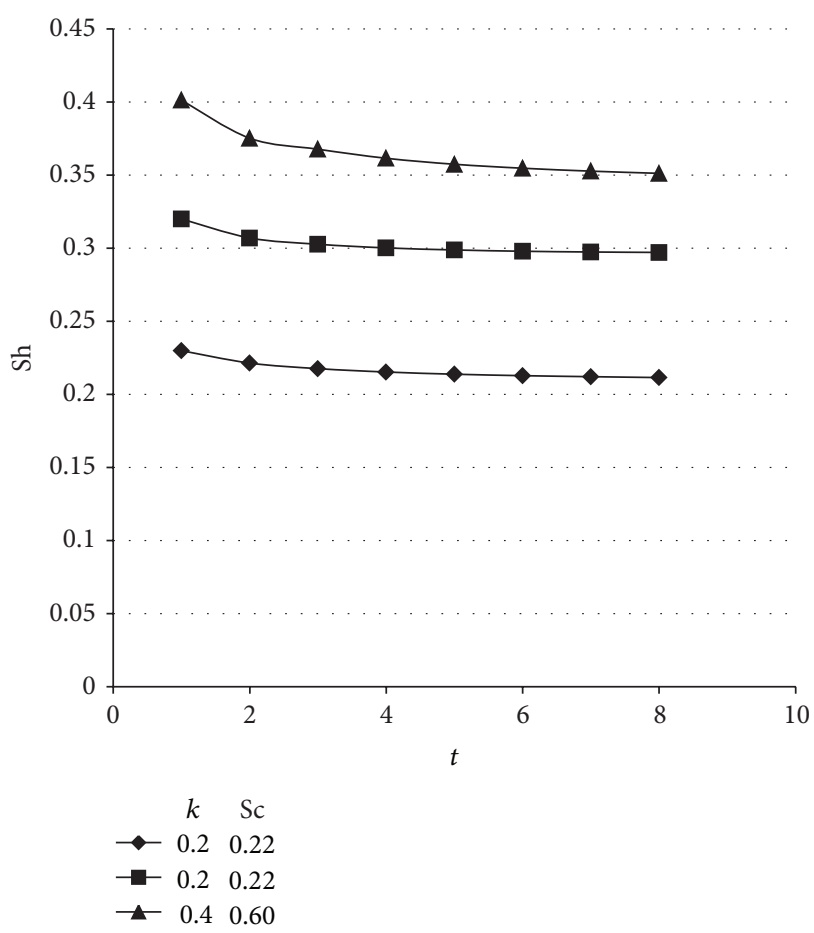

FIGURE 9: Sherwood number.

(3) Fluid velocity decreases with an increase in Schmidt number, phase angle, Prandtl number, and chemical reaction parameter but increases with an increase in Grashof number, modified Grashof number, and time. 
(4) There is a rise in skin friction with increasing Schmidt number, chemical reaction parameter, and phase angle and fall with an increase in value of modified Grashof number. The rate of heat transfer increases with an increase in the value of radiation parameter and Prandtl number. Sherwood number also increases with an increase in chemical reaction parameter and Schmidt number.

\section{Nomenclature}

$U_{R}:$ Reference velocity

$g$ : Gravitational acceleration

$C_{p}$ : Specific heat at constant pressure

$D: \quad$ Mass diffusivity

$\beta$ : Thermal expansion coefficient

$\beta_{C}$ : Concentration expansion coefficient

$\rho:$ Density

$\kappa$ : Thermal conductivity of fluid

$\kappa^{*}$ : Mean absorption coefficient

$\sigma$ : Electrical conductivity of fluid

$v$ : Kinematic viscosity

$q_{r}:$ Radiative heat flux

$\sigma^{\prime}$ : Stefan-Boltzmann constant

$L_{R}$ : Reference length

$t_{R}$ : Reference time

Gm: Modified Grashof number

Pr: Prandtl number

Sc: Schmidt number

$\omega$ : Frequency of oscillation

$u$ : Dimensionless velocity component

$\theta$ : Dimensionless temperature

$C:$ Dimensionless concentration

$\mu$ : Viscosity of fluid

$t$ : Time in dimensionless coordinate

$R: \quad$ Radiation parameter

$k$ : Chemical reaction parameter.

\section{References}

[1] S. T. Revankar, "Free convection effect on a flow past an impulsively started or oscillating infinite vertical plate," Mechanics Research Communications, vol. 27, no. 2, pp. 241-246, 2000.

[2] J. Li, D. B. Ingham, and I. Pop, "Natural convection from a vertical flat plate with a surface temperature oscillation," International Journal of Heat and Mass Transfer, vol. 44, no. 12, pp. 2311-2322, 2001.

[3] E. L. Cussler, Diffusion Mass Transfer in Fluid Systems, Cambridge University Press, Cambridge, UK, 1998.

[4] R. C. Chaudhary and J. Arpita, "Combined heat and mass transfer effect on MHD free convection flow past an oscillating plate embedded in porous medium," Romanian Journal of Physics, vol. 52, pp. 505-524, 2007.

[5] R. Muthucumaraswamy and A. Vijayalakshmi, "Effects of heat and mass transfer on flow past an oscillating vertical plate with variable temperature," International Journal of Applied Mathematics and Mechanics, vol. 4, pp. 59-65, 2008.

[6] R. Muthucumaraswamy, M. Raj Sundar, and V. S. A. Subramanian, "Unsteady flow past an accelerated infinite vertical plate with variable temperature and uniform mass diffusion," International Journal of Applied Mathematics and Mechanics, vol. 5, pp. 51-56, 2009.

[7] U. S. Rajput and S. Kumar, "MHD flow past an impulsively started vertical plate with variable temperature and mass diffusion," Applied Mathematical Sciences, vol. 5, no. 1-4, pp. 149-157, 2011.

[8] G. Juncu, "Unsteady forced convection heat/mass transfer from a flat plate," Heat and Mass Transfer/Waerme- und Stoffuebertragung, vol. 41, no. 12, pp. 1095-1102, 2005.

[9] U. N. Das, R. Deka, and V. M. Soundalgekar, "Effects of mass transfer on flow past an impulsively started infinite vertical plate with constant heat flux and chemical reaction," Forschung im Ingenieurwesen/Engineering Research, vol. 60, no. 10, pp. 284287, 1994.

[10] R. Muthucumaraswamy and S. Meenakshisundaram, "Theoretical study of chemical reaction effects on vertical oscillating plate with variable temperature, Theoret," Journal of Applied Mechanics, vol. 33, pp. 245-257, 2006.

[11] B. C. Neog and K. R. Das Rudra, "Unsteady Free Convection MHD Flow past a vertical plate with variable temperature and chemical reaction," International Journal of Engineering Research \& Technology, vol. 1, pp. 1-5, 2012.

[12] V. Rajesh, "Radiation effects on MHD free convection flow near a vertical plate with ramped wall temperature," International Journal of Applied Mathematics and Mechanics, vol. 6, pp. 6077, 2010.

[13] M. Muralidharan and R. Muthucumaraswamy, "Thermal radiation on linearly accelerated vertical plate with variable temperature and uniform mass flux," Indian Journal of Science and Technology, vol. 3, pp. 398-401, 2010.

[14] U. S. Rajput and S. Kumar, "Radiation effects on MHD flow past an impulsively started vertical plate with variable heat and mass transfer," International Journal of Applied Mathematics and Mechanics, vol. 8, pp. 66-85, 2012.

[15] R. C. Chaudhary and A. Jain, "Unsteady free convection flow past an oscillating plate with constant mass flux in the presence of radiation," Acta Technica CSAV, vol. 52, no. 1, pp. 93-108, 2007.

[16] A. Ogulu and O. D. Makinde, "Unsteady hydromagnetic free convection flow of a dissipative and radiating fluid past a vertical plate with constant heat flux," Chemical Engineering Communications, vol. 196, no. 4, pp. 454-462, 2009.

[17] M. Narahari and L. Debnath, "Unsteady magnetohydrodynamic free convection flow past an accelerated vertical plate with constant heat flux and heat generation or absorption," Zeitschrift für Angewandte Mathematik und Mechanik. Applied Mathematics and Mechanics, vol. 93, pp. 38-49, 2013.

[18] R. C. Chaudhary and J. Arpita, "Free convection effects on MHD flow past an infinite vertical accelerated plate embedded in porous media with constant heat flux," Matematicas, pp. 7382, 2009.

[19] B. M. Abramowitz and I. A. Stegun, Handbook of Mathematical Functions, Dover, New York, NY, USA, 1970. 

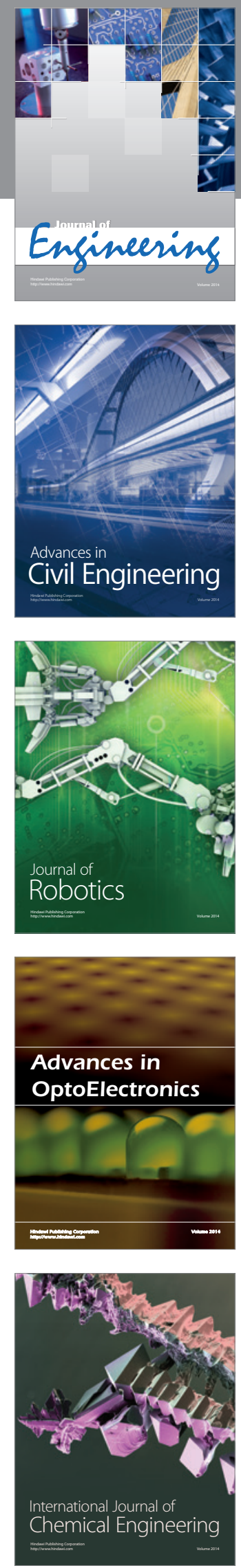

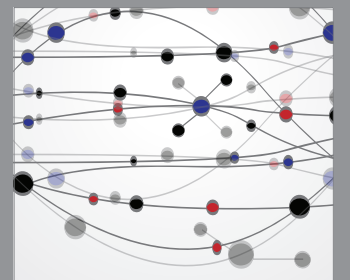

The Scientific World Journal
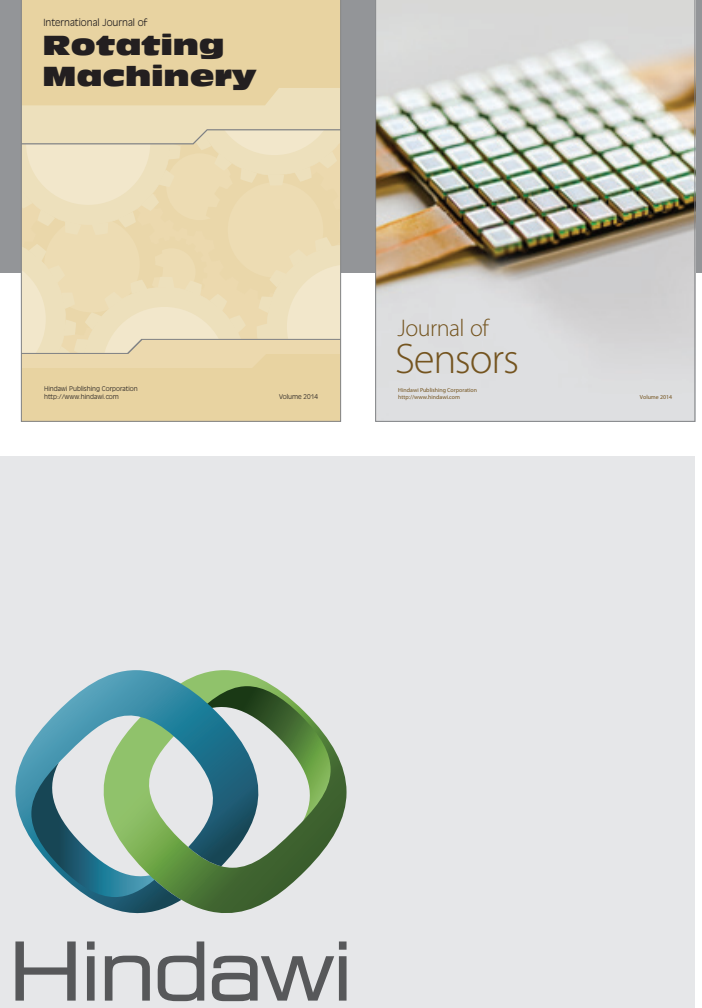

Submit your manuscripts at http://www.hindawi.com
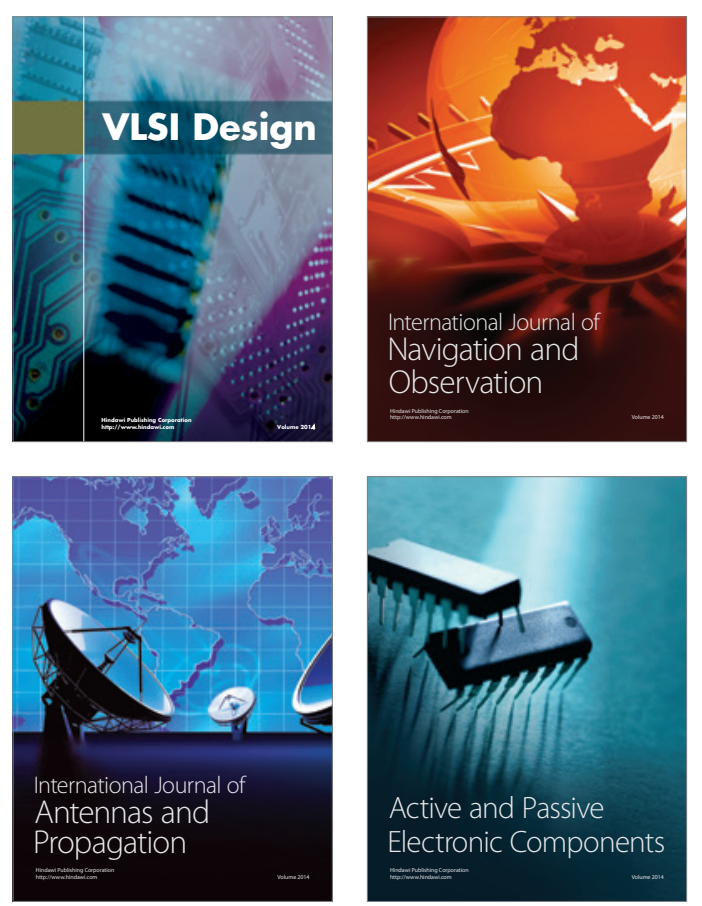
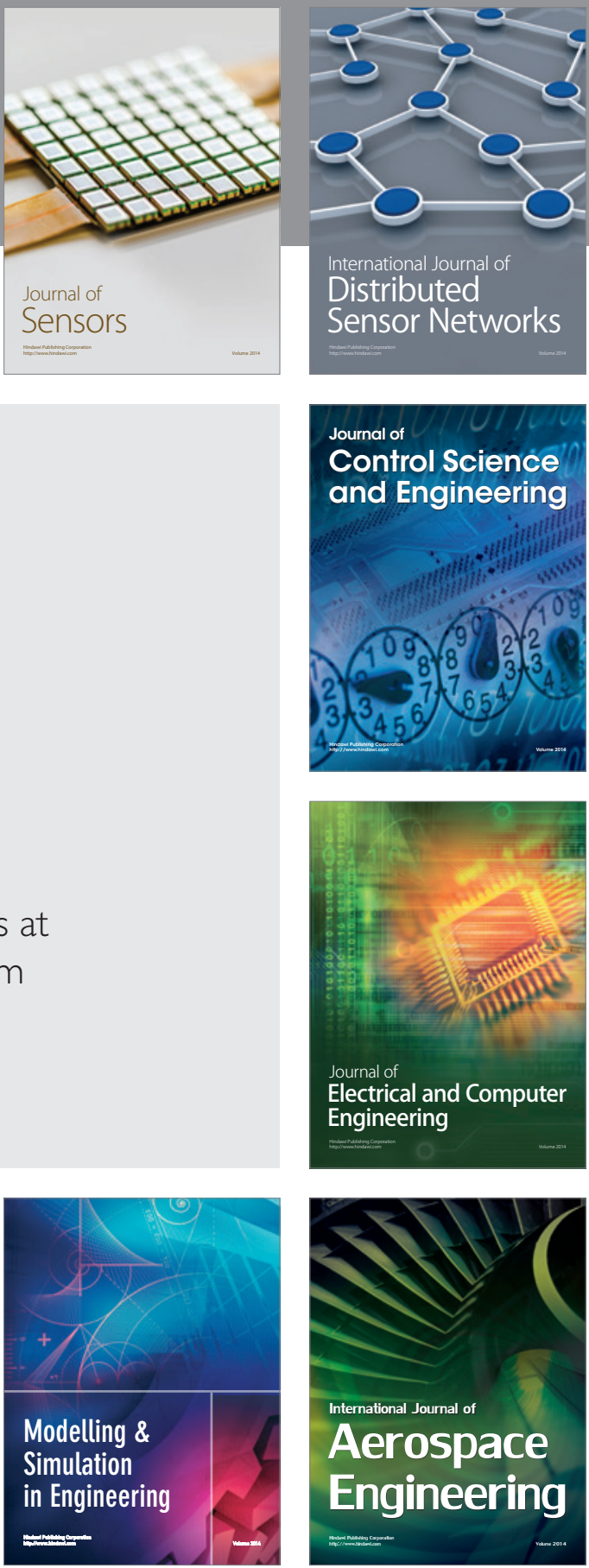

Journal of

Control Science

and Engineering
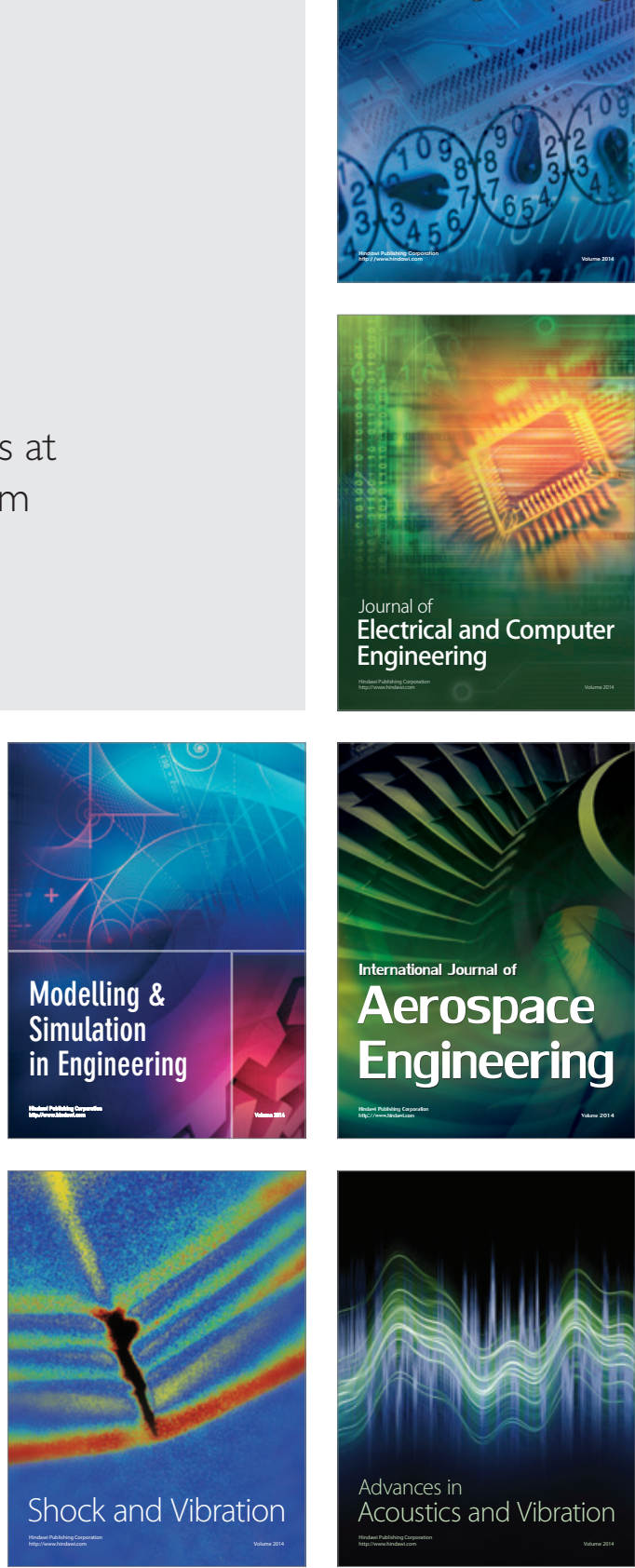